\title{
Folguedos juninos: o ensino da dança sob a perspectiva das dimensões dos conteúdos
}

\author{
Pollyane Barros Albuquerque Vieira? \\ Elisabete dos Santos Freire ${ }^{2}$ \\ Graciele Massoli Rodrigues ${ }^{3}$
}

\section{RESUMO}

A educação física teve, e ainda tem, uma forte predominância do conteúdo esporte na escola. A partir da década de 1990, surgem novas contribuições na educação física, com novos temas/conteúdos nas aulas. Entretanto, a dança ainda é pouco frequente nas aulas de educação física escolar. O presente relato de experiência tem por objetivo ressignificar a prática pedagógica da dança, numa relação dialógica entre professor e aluno. A análise teve como cenário um Projeto Interdisciplinar onde foram vivenciados dois conteúdos: a quadrilha e o carimbó. Identificamos a ressignificação do conteúdo dança com uma vivência que transcende o "saber fazer", e, uma oportunidade de refletir sobre os aspectos de gênero, sexualidade e diversidade religiosa.

Palavras-chave: Dança. Educação física escolar. Dimensões dos conteúdos.

1 Doutoranda em Educação Física. Professora do ensino básico, técnico e tecnológico do Instituto Federal de Educação, Ciência e Tecnologia do Pará (IFPA). Belém/Pará, Brasil. E-mail: pollyanebarros@hotmail.com

2 Doutora em Educação Física. Professora nos Cursos de Graduação e de Pós Graduação Stricto Sensu em Educação Física da Universidade São Judas Tadeu (USJT). São Paulo/São Paulo, Brasil.

E-mail: elisabetefreire@uol.com.br

3 Doutora em Educação Física. Professora titular da Escola Superior de Educação Física de Jundiaí e no Programa de Pós Graduação Stricto Sensu em Educação Física e em Ciências do Envelhecimento da Universidade São Judas Tadeu (USJT). São Paulo/São Paulo, Brasil. E-mail: masgra@terra.com.br

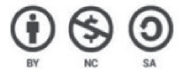

Este texto está publicado sob uma licença Creative Commons Atribuição NãoComercial-Compartilhalgual - CC BY NC AS

Mais detalhes em: https://br.creativecommons.org/licencas/ 
Typical dances: the teaching of dance from the perspective of the dimensions of the contents

\begin{abstract}
Physical education has had and remains a strong predominance of sports contents at school. From the 1990s, new contributions emerge in physical education, with new themes / content in the classes. However, the dance still infrequent in school's physical education classes. This report of experience aims to re-signify the practice of pedagogy of dance, in a dialogical relationship between teacher and student. The analysis was based on an Interdisciplinary Project where lived two contents: the "quadrilha" and the "carimbo". We identified the redefining the dance content with an experience that transcends the "Know-how", and an opportunity to reflect on the gender aspects, sexuality and religious diversity.
\end{abstract}

Keywords: Dance. Physical education classes,. Dimensions of the contents.

Danzas tipicas: la enseñanza de la danza, bajo la perspectiva de las dimensiones de los contenidos

\title{
RESUMEN
}

La educación física ha tenido, y aún tiene, un fuerte predominio del contenido deporte en la escuela. A partir de la década de 1990, surgen nuevas contribuciones en la educación física, con nuevos temas / contenidos en las clases. Sin embargo, la danza sigue siendo poco frecuente en las clases de educación física. El presente relato de experiencia tiene por objetivo resignificar la práctica pedagógica de la danza, en una relación dialógica entre profesor y alumno. El análisis tuvo como escenario un Proyecto Interdisciplinario donde fueron vivenciados dos contenidos: la "quadrilha" y el "carimbo". Identificamos la resignación del contenido danza con una vivencia que trasciende el contenido "Saber hacer", y una oportunidad de reflexionar a cerca de los aspectos de género, sexualidad y diversidad religiosa.

Palabras clave: Danza. Educación física escolar. Dimensiones de los contenidos. 


\section{INTRODUÇÃO}

O Brasil é marcado pela diversidade cultural, entretanto, ainda pouco conhecido pelos próprios habitantes do país. A região norte, é coberta de mitos, mistérios e oportunidades. As oportunidades e atrativos como é o caso da doação de terras e o garimpo, por exemplo, despertaram o interesse dos migrantes para a região.

Infelizmente a mídia reforça o imaginário popular com notícias que revelam as mazelas, o tráfico de drogas, e os conflitos agrários. Entretanto, antes de revelar os detalhes do projeto "Arraial do Campus Rural de Marabá" se faz necessário entender o contexto e os sujeitos protagonistas do referido momento.

O Campus Rural de Marabá (CRMB) é uma das unidades do Instituto Federal de Educação, Ciência e Tecnologia do Pará (IFPA) e está localizado a $25 \mathrm{~km}$ da sede do município de Marabá, na PA-150, em uma área de 354 hectares. Devido a sua localização, integrado ao projeto de assentamento (PA 26 de Março), contribui no tocante a formação de profissionais, geração e difusão de conhecimentos e tecnologias para atender a demanda da agricultura familiar e comunitária.

O CRMB destina-se a atender, prioritariamente, aos povos do campo - agricultores familiares, camponeses, agroextrativistas, quilombolas, indígenas, pescadores artesanais, ribeirinhos e trabalhadores rurais assalariados sindicalizados. Oferece cursos em diferentes modalidades: no ensino superior, a licenciatura plena em educação do campo; no PROEJA, o curso de qualificação profissional em agricultura familiar com ênfase em agroecologia; e, dois cursos técnicos, integrados ao ensino médio - agroecologia e agropecuária.

Diante da especificidade desse contexto e da população a qual atende, o CRMB busca amparo nos artigos 23 e 28 da Lei 9.394/96 - Lei de Diretrizes e Bases da Educação Nacional (LDB) - que prevê o atendimento em regime especial e adota como referência metodológica a denominada "alternância pedagógica".

A alternância pedagógica busca garantir o acesso à educação observando as diferenciações próprias da realidade do campo e de seus sujeitos, como por exemplo, a possibilidade de organização de um calendário escolar regionalizado que considere as condições climáticas, econômicas e, trabalho e fases do ciclo agrícola, bem como adequação de propostas curriculares contextualizadas.

Diante desse contexto peculiar, no qual o CRMB está inserido, foi proposto um Projeto intitulado: Arraial do CRMB. A atividade envolveu oitenta e cinco alunos, todos matriculados em duas turmas do curso técnico em agropecuária, integrado ao ensino médio, e uma professora de educação física.

Assim, o presente trabalho pretende apresentar o relato da experiência de aulas de educação física, cujo tema era as danças do ciclo junino. Tal projeto teve alicerce a partir do diálogo entre os protagonistas do processo de ensino-aprendizagem: alunos e professora.

\section{O arraial CRMB - um projeto em construção}

Tomando como referência o contexto dos envolvidos no projeto, professora e alunos, e diante dos novos olhares que visitam a educação física, que indica uma abordagem 
que ultrapassa o puro e simples "exercitar o físico", surgiu a necessidade de uma intervenção pedagógica mediada pelo diálogo.

De acordo com Paes (2011) as práticas educativas requerem novas formas de ensinar pautadas no diálogo e na troca de experiências entre aluno e professor. Nessa perspectiva horizontal, de diálogo e de participação colaborativa do aluno, o processo de educação é dialógico e possibilita a eles desenvolver suas potencialidades de comunicação e de construção do saber.

O projeto "Arraial do CRMB" teve início com a escolha do tema. Essa escolha não ocorreu ao acaso. Algumas questões foram levadas em consideração, por exemplo: a grande quantidade de alunos migrantes de outros estados, inclusive, a professora; a falta de acesso, às aulas de educação física por parte de alguns alunos, em anos anteriores; e, devido à disparidade da faixa etária dos alunos que variava entre 15 e 40 anos de idade.

Com a finalidade de caracterizar o perfil e os interesses da turma e, posteriormente, propor um plano de trabalho mais significativo, foi realizada no início do ano letivo, uma avaliação diagnóstica. A partir dessa intervenção identificaram-se os conteúdos abordados em anos anteriores e, principalmente, aqueles temas que eram mais significativos para os alunos.

Simplesmente, não podemos chegar aos operários, urbanos ou camponeses, estes, de um modo geral, imersos num contexto colonial, quase umbilicalmente ligados ao mundo da natureza de que se sentem mais partes que transformadores, para à maneira da concepção "bancária", entregar-lhes "conhecimento" ou impor-lhes um modelo de bom homem, contido no programa cujo conteúdo nós mesmos organizamos (FREIRE, 1978, p.48).

Ao buscar uma temática que emergiu do interesse do aluno, no sentido de valorizar tais manifestações, buscou-se estabelecer uma relação horizontal de diálogo entre professor e aluno, onde a construção do saber se dá em via dupla. É o que Freire (1978) denomina de educação autêntica. Para o autor a construção do conhecimento, não se consolida na relação em que o professor é a única autoridade detentora do conhecimento. Tal processo se constrói de maneira dialógica do professor com o aluno, na qual ambos são detentores de conhecimento.

A dança foi um tema, dentre os diversos temas sugeridos, que estava presente na avaliação diagnóstica. A quadrilha junina, do nordeste do Brasil - tendo em vista a quantidade de migrantes dessa região - como o carimbó, do Pará, despertaram o interesse da turma. Em decorrência dessa participação ativa do aluno, o planejamento foi reestruturado e o projeto "Arraial CRMB" foi construído.

Nestas circunstâncias, o Projeto "Arraial CRMB" foi proposto tomando como referência, o seguinte planejamento inicial: 


\begin{tabular}{|c|c|}
\hline Tema: Dança & Carga Horária: $24 \mathrm{~h} / \mathrm{a}$ \\
\hline \multicolumn{2}{|c|}{ Objetivo: conhecer e vivenciar as danças do ciclo junino (quadrilha junina e carimbó) } \\
\hline \multirow[t]{3}{*}{ Conteúdos } & $\begin{array}{l}\text { Conceituais: conhecer o contexto histórico e sociocultural, os } \\
\text { grupos étnicos que influenciaram, a música, os instrumentos e } \\
\text { indumentárias característicos dos folguedos. }\end{array}$ \\
\hline & $\begin{array}{l}\text { Procedimentais: vivenciar os passos básicos e noções de } \\
\text { montagem coreográfica. }\end{array}$ \\
\hline & $\begin{array}{l}\text { Atitudinais: conhecer e apreciar a dança, discutir as questões } \\
\text { de gênero e os preconceitos que permeiam a prática da } \\
\text { dança, estimular o trabalho e a cooperação entre o grupo. }\end{array}$ \\
\hline $\begin{array}{l}\text { Procedimentos didático- } \\
\text { metodológicos }\end{array}$ & $\begin{array}{l}\text { - Aulas-expositivas: resgate do conhecimento prévio do } \\
\text { aluno sobre a temática, apresentação do projeto, aula } \\
\text { teórica com utilização de texto didático e apresentação de } \\
\text { vídeos sobre a temática. } \\
\text { • Oficinas de dança: apresentação dos passos básicos e } \\
\text { noções de montagem coreográfica. }\end{array}$ \\
\hline $\begin{array}{l}\text { Instrumentos } \\
\text { avaliativos }\end{array}$ & $\begin{array}{l}\text {-Elaboração de coreografia para apresentação (carimbó e } \\
\text { - Fuadrilha junina); } \\
\text { - Avaliaçãa escrita e individual. }\end{array}$ \\
\hline
\end{tabular}

Com a finalidade de organizar essa intervenção, foi elaborado um texto didático. Tal instrumento teve o objetivo de oferecer aos alunos informações sobre a temática, além de orientar para as etapas do processo avaliativo. Dessa forma apresentou-se como um apoio bibliográfico que pode ser utilizado para além da carga horária de sala.

\section{A execução - "o durante"}

No início do tempo-escola ${ }^{4}$ o projeto foi apresentado aos alunos, os quais receberam com bastante interesse. Houve, primeiramente, explanação teórica com as principais informações sobre a proposta do tema, os objetivos, a metodologia de trabalho, e o processo avaliativo. No momento de aula, os alunos sugeriram que a apresentação das coreografias não acontecesse durante a aula de educação física, e sim durante uma festa junina, organizada por eles.

Por isto o diálogo é uma exigência existencial. E, se ele é o encontro em que se solidariza o refletir e o agir de seus sujeitos endereçados ao mundo a ser transformado e humanizado, não pode reduzir-se a um ato de depositar ideias de um sujeito no outro, nem tampouco tornar-se simples troca de ideias de serem consumidas pelos permutantes (FREIRE, 1978, p. 45).

4 O Projeto Politico Pedagógico do CRMB é caracterizado por dois locus de aprendizagem. Um deles é o tempo-escola desenvolvido durante o período que os alunos estão nas dependências da instituição. O outro é denominado de tempo-comunidade que compreende atividades orientadas para serem desenvolvidas nas comunidades de origem, as atividades são supervisionadas pelos professores da instituição. 
Dessa forma, a partir do diálogo, o Arraial do CRMB foi constituído, com a participação dos sujeitos envolvidos no processo e sem a imposição de forças. Frente às sugestões apresentadas pelos alunos, foi necessário reorganizar a intervenção e o processo avaliativo.

Para que a festa fosse incorporada ao projeto, seria necessário o envolvimento de todos. Assim, foi proposta a distribuição dos alunos em seis grupos de trabalho (alimentação/ serviço, decoração, cerimonial, som, recreação e limpeza) para a organização do Arraial. Nessa perspectiva, buscou-se de maneira dialogada a escolha dos conteúdos adequados para realização do projeto.

[...] para o educador-educando, diálogo, problematizador, o conteúdo programático da educação não é uma imposição - conjunto de informes a ser depositado nos educandos - mas a revolução organizada, sistematizada e acrescentado ao povo, daqueles elementos que este lhe entregou de forma desestruturada (FREIRE, 1978, p. 47).

Em virtude da nova configuração do projeto, foi incorporado mais um instrumento avaliativo. Assim, a avaliação foi composta pela elaboração e apresentação de coreografia, por uma prova escrita e por uma ficha de autoavaliação dos grupos de trabalho.

A avaliação prática era composta pela apresentação de duas coreografias - carimbó e quadrilha - nas quais seriam observados os seguintes critérios: a utilização de passos característicos de cada dança, adereços e indumentárias; utilização/organização no espaço; criatividade da coreografia; entrosamento dos participantes.

A avaliação escrita constituía-se de uma prova com questões objetivas e subjetivas na qual se buscou verificar a apreensão de alguns conceitos básicos abordados durante as aulas, discussões e por meio da leitura do texto didático utilizado durante o projeto e, sobretudo, qual a contribuição efetiva do conteúdo para cada um dos alunos.

Por fim, a ficha de autoavaliação constituía-se de um instrumento cuja intenção era que os grupos de trabalho refletissem e avaliassem o desempenho dos componentes, diante das dificuldades, facilidades, erros e acertos durante a construção e execução do projeto Arraial CRMB.

\section{As oficinas de dança e as dimensões dos conteúdos.}

Após as adequações no projeto e as aulas expositivas, foram iniciadas as oficinas de quadrilha junina e carimbó. Em cada uma delas foram abordados os passos, movimentações básicas e noções de composição coreográfica. As oficinas tiveram como ponto de partida o conhecimento prévio que os alunos possuíam acerca das temáticas.

Tal premissa pretendia estabelecer um diálogo entre os protagonistas do projeto (professora-alunos), bem como, provocar a reflexão sobre o ambiente escolar, uma vez que, como sugere Vago (2009), o espaço de aprendizagem e os envolvidos nesse processo compõem um lugar de culturas, das culturas e entre culturas. 
[...] lugar de culturas porque seus protagonistas [...] são produtores de culturas [...] São também produzidos nas culturas em que estão envolvidos: sua condição de classe, seu pertencimento étnico, seu gênero, a escolha de sua sexualidade, são marcas de suas histórias, significantes para suas vidas. [...] é um lugar de circulação das culturas porque tem como responsabilidade realizar o humano direito a um patrimônio por todos produzido: conhecer, fruir e usufruir as culturas diversas produzidas pelos humanos. [...] lugar entre as culturas porque estabelece relações com outros lugares em que os humanos produzem suas culturas - nas ruas, nas praças, nos pertencimentos religiosos, na política, nas tantas manifestações artísticas, por exemplo (VAGO, 2009, p. 28).

Durante as oficinas, alguns conflitos surgiram relacionados às questões de gênero/ sexualidade/religião. O primeiro deles vinculava a prática da dança à delicadeza, à feminilidade e ao homossexualismo. Como a quantidade de alunos (sexo masculino) era superior em número, e a maioria das movimentações do carimbó e da quadrilha junina são realizadas aos pares, houve inicialmente uma grande resistência em participar das oficinas.

Outro pequeno grupo, por questões religiosas, criou resistência em aderir ao projeto, pois enxergava a dança como a uma prática pecaminosa e, no caso específico da quadrilha, como uma a celebração aos Santos da Igreja Católica.

De acordo com Kunz (2001) por meio do ensino da educacao fisica, espera-se que o aluno seja capaz de compreender além da realidade do movimento, o próprio contexto social mais amplo, no qual se realiza. Assim, diante da apresentação desses conflitos, foram utilizadas dois recursos didáticos para mediar o debate sobre essas questões: a exibição de um filme e, a leitura de trechos bíblicos.

O vídeo apresentava a dança dos cossacos que é originária da Rússia, e exclusivamente praticada por homens. Entre outras particularidades, os dançarinos desafiam-se por meio de sequências de saltos malabarísticos e de agachamentos. Em seguida, houve o incentivo para que voluntários demonstrassem alguma das movimentações apresentadas no vídeo.

Posteriormente, foi realizada a leitura de alguns trechos bíblicos, nos quais a dança é utilizada para estabelecer o contato com o divino, para celebrar, ou ainda, para agradecer pelos ganhos e conquistas.

Como conseqüência dessas duas estratégias, iniciou-se um debate e os alunos começaram a repensar alguns pontos de vista. Eles começaram a perceber a dança e suas possibilidades de comunicação.

Essas experiências permitiram que os alunos percebessem o quanto de força fisica e vigor estão envolvidos nesses movimentos, e repensassem uma visão distorcida que determina que o homem que dança é delicado ou homossexual.

[...] isto deve significar que pelo ensino dos Movimentos, Jogos e Esportes, o aluno também apreenda e "decifre" além da Realidade esportiva, o próprio Contexto Social mais amplo, em que a prática se realiza (KUNZ, 2001, p.149).

Apesar de não estar previsto, dentre os objetivos do projeto esse tipo de discussão, não se pode deixar tal oportunidade escapar. Durante as oficinas, a partir da vivências/ 
execução dos passos e movimentações básicas, surgiram algumas discussões sobre a delicadeza/feminilidade associada à dança, bem como, uma visão pecaminosa da prática defendida por algumas religiões.

Através do permanente diálogo, os saberes foram constituídos a partir da ressignificação do conteúdo dança, uma vez que durante as aulas, através do estudo de textos e vídeos e da mediação do debate, as visões deturpadas que associavam, por exemplo, a homossexualidade e o pecado à dança, começaram a ser desconstruídas.

Para instigar o debate e a reflexão, diante da associação da dança a uma manifestação pecaminosa, foi utilizado, por exemplo, a leitura de alguns versículos da Bíblia, os quais relatavam o uso da dança como veículo de contato com o divino e mecanismo de oferta e agradecimento dos desejos aspirados e alcançados.

No que se refere à associação da dança à delicadeza e ao feminino foi proposto alguns vídeos, com apresentações de dança, como por exemplo, das danças cossacas, às quais em sua maioria é praticada por homens e compreende evoluções coreográficas que exacerbavam virilidade, uma vez que as evoluções (salto, saltitos, mudança de direção associada a agachamentos) requerem bastante força, sobretudo, dos músculos abdominais e dos membros inferiores, um contraponto a percepção de fragilidade, delicadeza, inicialmente associada à dança.

\section{A avaliação - "desdobramentos"}

No dia da execução do projeto o CRMB foi invadido por um forte sentimento de trabalho coletivo e, todos os protagonistas estavam envolvidos na criação do Arraial do CRMB, desde a preparação das comidas típicas, até a decoração do pátio, organização das barracas recreativas, entre outros.

A partir dos instrumentos avaliativos (prova prática, escrita e trabalho em grupo) algumas constatações puderam ser verificadas, no que se refere ao conteúdo que norteou o projeto.

Durante a apresentação coreográfica, observou-se a presença dos passos e movimentações básicas, características dos folguedos, a criação/ adaptação de movimentações, bem como, uma boa organização no espaço e noções de ritmo, conforme os critérios avaliativos propostos.

Sem desprestigiar a vivência dos gestos motores em si, característicos das manifestações, não se pode deixar de mencionar que as aprendizagens foram além da dimensão procedimental. O conteúdo possibilitou uma intervenção relevante e notória nas dimensões conceituais e atitudinais.

A compreensão do conteúdo transcendeu a simples execução de movimentos, uma vez que os relatos e vivências revelam a apreensão de dados sobre questões históricas, sociais e conceituais das manifestações da cultura corporal e dos sujeitos envolvidos, na prática do carimbó e da quadrilha. 
No que se refere as atitudes e valores, os relatos relevaram uma mudança de percepção em relação ao conteúdos dança, uma vez que começaram a enxergá-la como uma possibilidade de expressão e comunicação e, não exatamente, uma expressão do pecado e, enxergar que a execução das coreografias requerem bastante força, em contraponto a delicadeza, anteriormente associada a ela.

\section{CONSIDERAÇÕES FINAIS}

O projeto Arraial do CRMB foi uma atividade que proporcionou uma releitura da prática profissional, a partir do olhar crítico para a experiência vivida enquanto aluna da escola básica.

Essa revisita possibilitou uma ressignificação do conteúdo dança, nas aulas da educação física, uma vez que a abordagem ultrapassou a mera execução do gesto motor e possibilitou uma reflexão sobre os conceitos e atitudes que permeiam tais manifestações.

Tal intervenção só foi possível a partir de uma prática dialógica, na qual os protagonistas - professora e alunos - educam e são educados com os outros, em outras palavras, uma estratégia que valoriza o conhecimento do aluno e, que além de promover uma participação colaborativa, pode promover a autoestima dos alunos.

Outro ponto relevante é escutar a voz do aluno enquanto sujeito de cultura. Sujeito que produz, que é resultado e, que estabelece relações com a cultura. Nessa mesma perspectiva, não apenas o professor, mas os alunos tornaram-se protagonistas do processo de consolidação do projeto.

O planejamento e, sobretudo, a execução de um projeto como esse envolve bastante trabalho, envolvimento e a necessidade permanente de refletir, reavaliar e replanejar a prática pedagógica. Entretanto, é extremamente gratificante perceber a ressignificação do conteúdo dança, através de uma prática dialógica, em que a vivência do gesto motor ultrapassou o espaço da sala de aula e tomou conta de toda a escola, sem contar, ainda, que transcendeu os procedimentos e, atingiu as dimensões conceituais e atitudinais dos conteúdos.

\section{REFERÊNCIAS}

BRASIL. Lei Federal nº 9.394 - Lei de Diretrizes e Bases da Educação Nacional. 1996.

FREIRE, Paulo. Pedagogia do oprimido. 6 ed. Rio de Janeiro: Paz e Terra, 1978.

IFPA/CRMB. Projeto Político Pedagógico Campus Rural de Marabá. Marabá, 2010.

KUNZ, Elenor. Educação física: ensino \& mudanças. 2.ed. ljuí: Ed. Unijuí, 2001.

OLIVEIRA, Rogério Cruz; DAOLIO, Jocimar. Educação intercultural e Educação Física escolar: possibilidades de encontro. Pensar a Prática: Goiânia, v. 14, n. 2, p. 1-11, maio/ago. 2011. 
setembro/2018

PAES, Salete Dubra. O lugar das práticas dialógicas no ensino da língua inglesa. Pesquisa em Pós-Graduação - Série Educação, v. 3, n. 6, p. 113-120, 2011.

VAGO, Tarcisio Mauro. Pensar A Educação Física na escola: para uma Formação cultural da infância e da juventude. Cadernos de Formação RBCE, p. 25-42, set. 2009.

Recebido em: Junho/2017

Aprovado em: Janeiro/2018 